\title{
Un ejemplo de caciquismo electoral en el País Vasco: el comité liberal de Bilbao (1881-1899)
}

\author{
Javier Real Cuesta (*)
}

\section{CONTEXTO Y SIGNIFICACIÓN HISTÓRICA}

La primera consulta electoral celebrada en el Pais Vasco con intervención del carlismo tras la última contienda, puso de manifiesto la polarización, la división ideológico-política de la sociedad vasca entre carlismo/liberalismo, división por otra parte caracteristica durante la mayor parte del siglo XIX que la guerra no habia logrado superar y que continuaria hasta la primera década del siglo $x x$ '. En las elecciones provinciales celebradas en 1880 los carlistas consiguieron la mayoría absoluta en la Diputación de Álava y minorias mayoritarias en las de Guipúzcoa y Vizcaya (nueve y ocho diputados sobre 20), mientras que los liberales por su parte concurrieron divididos y obtuvieron representaciones minoritarias $^{2}$. No deja de ser paradójico que, cuatro años después de haber sido derrotado militarmente, el carlismo volviera a controlar las nuevas Diputaciones Provinciales. Caso de persistir la situación, el dominio carlista de las restantes instituciones politicas estaria asegurado.

La posibilidad de que el carlismo dominara las instuciones tras las próximas elecciones locales y generales de 1881, hizo reaccionar a los grupos y corrientes liberales de las tres provincias, intentando formar frentes anticarlistas. En Álava y Guipúzcoa, las uniones fueron, salvo mo-

* Universidad de Deusto. Bilbao

Véase Real Cuesta, Javier, Partidos, elecciones y bloques de poder en el Pais Vasco (1876-1923). Bilbao, Universidad de Deusto, 1992.

2 Pueden verse los resultados en Real Cuesta, Javier, El Carlismo vasco, 1876-1900. Madrid, Siglo XXI, 1985, pág. 46. 
mentos puntuales, precarias y frágiles, planteándose todos los intentos sobre la base de la unión de la totalidad de fuerzas liberales (aunque pivotando sobre los republicanos moderados y los dinásticos avanzados), en Vizcaya por el contrario, consiguieron permanecer unidos durante la década de los ochenta, si bien ésta afectaria únicamente a las corrientes dinástico-liberales, quedando los republicanos relegados.

El instrumento unitario de los dinásticos vizcaínos sería el «Comité Liberal de Bilbao", organización que, como hemos puesto de relieve en un reciente estudio ${ }^{3}$ caracterizaria la politica vizcaina durante la década de los ochenta. En este articulo pretendemos analizar su actividad electoral por cuanto «constituye un ejemplo de los métodos electorales utilizados en el País Vasco antes de la década de los noventa". Hemos utilizado para este propósito la documentación de Victoria de Lecea, uno de los miembros mas significados del Comité, conservada en la Cámara de Comercio de Bilbao ${ }^{4}$.

\section{ORGANIZACIÓN E IDEOLOGÍA}

Con ocasión de la celebración de las elecciones municipales de 1881 , 77 personalidades de significación dinástico-liberal convocaron a todos aquellos individuos que sintonizasen con esta corriente a una reunión a celebrar el 25 de abril en Bilbao. Los reunidos nombraron un Comité con el encargo

«... no solamente de la formación de la candidatura para concejales que entonces debia votarse en esta villa, sino también de las que más tarde fuera preciso votar para senadores y diputados a Cortes en Vizcaya. Autorizábasele al propio tiempo a llevar a cabo según las circunstancias to exigieran, cuantos trabajos fuesen necesarios para la reorganización del partido liberal (...).

Atento al cumplimiento de este acuerdo, formó el Comité la candidatura que obtuvo un triunfo brillante. De poco serviria este resultado sino se pensara en organizar trabajos fundados en sólidas y duraderas bases (...). Cree el Comité que el medio mas práctico y sencillo para atender a los gastos que se originen, es abrir una suscripción en la cual

\footnotetext{
3 Real Cuesta, Javier, Partidos..

4 ARCE, Andrés, LoPEZ, Anuncia, "Archivo "Victoria de Lecea": una familia liberal en el entorno carlista del siglo xx", Letras de Deusto Vol. $14, \mathrm{n}^{\circ}{ }^{\circ} 29$, mayo-agosto 1984 , págs. 93117.
} 
cada uno según su voluntad se suscriba por una cantidad mensual, comprendida entre una y cinco pesetas. (...)". Firmas: Eduardo Victoria de Lecea como presidente y 34 más ${ }^{5}$.

El Comité, presidido por Eduardo Victoria de Lecea, quedó compuesto por 35 miembros, actuando eficazmente en la organización de las elecciones municipales de 1881 a tenor de los resultados obtenidos. Celebradas éstas, y de acuerdo con el mandato inicial, desplegó una intensa actividad en la corganización de trabajos fundados en sólidas y duraderas bases»: adquirió un local como sede, instalaron una oficina permanente, fijaron una cuota mensual de abono para los socios (entre una y cinco pesetas) y alentaron la constitución de Juntas o Comités locales. De acuerdo con sus instrucciones, en los años siguientes se constituirian Comités en las localidades de Bermeo, Ea, Deusto, Plencia, Zamudio y Rigoitia ${ }^{6}$.

El "Comité ejecutivo", compuesto por un número variable de miembros (35 al principio y siete en 1890) elegidos por una Junta General de socios, era el órgano encargado de la dirección; funcionaron además Comités Electorales con carácter ocasional nombrados por el Comité ejecutivo. La financiación corria a cargo de los socios a través de cuotas y otras cantidades aportadas voluntariamente por determinados socios o simpatizantes $^{7}$; aún cuando la cuantía de la cuota era reducida, su misma existencia representa una novedad respecto de las fórmulas utilizadas por el resto de las fuerzas políticas. Los gastos electorales eran financiados conjuntamente por el Comité y los candidatos, dependiendo su aportación de la capacidad económica de éstos.

El número de afiliados fue disminuyendo con los años. En base a las cuotas establecidas, calculamos para el año 1883 unos 198 miembros al corriente del pago de las mismas, número que bajaria en 1890 a 134 y a 133 en 1891. En cuanto a los afiliados incluidos en los comités locales, no contamos con datos precisos pero, si consideramos que el de Deusto contaba con 13, bien podemos pensar que no sobrepasarian las dos o tres decenas. De todos modos, el número de miembros es un dato de interés

Archivo Victoria de Lecea (AVL), leg. 10 doc. 62, 27 junio 1881.

AVL., Leg. 10., doc., 62, 27 junio 1881.

«Si usted - decia en su carta el Comité- acepta estas ideas, sirvase inculcarlas en el ánimo de sus amigos y proceder de acuerdo con ellos a la constitución inmediata de una Junta o Comité en esa localidad dando cuenta del resultado. Será conveniente que, al constituirse ese comité, designe persona que le represente permanentemente en el central, que sirva de intermediaria y a la par de procurador directo de los intereses locales. Ibidem, doc. 79, 4 octubre 1881. 
relativo para considerar el peso real del Comité pues su influencia se ampliaba a círculos de amigos o conocidos a los cuales se dirigia cuando lo consideraba necesario.

En cuanto a su programa ideológico, los Manifiestos emitidos especialmente durante los primeros años con ocasión de las consultas electorales, ponen de manifiesto la primacia de los intereses económicos sobre los ideológicos o, cuando menos, la subordinación de éstos. En 1884, después de expresar su satisfacción por la «vida lozana y próspera» que atravesaba la provincia, expusieron los medios a su juicio adecuados para su desenvolvimiento: aplicación de las leyes generales de la Nación $y$, con especial énfasis, “afianzamiento de los Conciertos Económicos», a los cuales se deberia dotar de mayor concreción y seguridad jurídica. Este entusiasmo de la burguesia por el Concierto resultaba lógica tras la constatación de unos efectos que favorecian sus intereses económicos. Los Fueros son sólo objeto de referencias vagas, genéricas y con condiciones, pues solicitan su restablecimiento, "siempre que sean aplicables a las necesidades de los tiempos y al presente estado de los negocios públicos". Al igual que las referencias acerca del carlismo, del cual destacan únicamente su incompatibilidad con el progreso económico. En definitiva, el liberalismo como referencia filosófica y politica, el anticarlismo militante tan caracteristico de los liberales de las otras provincias, deja paso aqui al pragmatismo y la preocupación por las cuestiones económicas.

\section{ORGANIZACIÓN DE LAS ELECCIONES}

Como indicamos, la finalidad principal del Comité era la de organizar las elecciones: designaba las candidaturas y se encargaba de realizar, en colaboración con los candidatos, todos los trabajos electorales. Aunque en la mayor parte de las elecciones, el Comité Ejecutivo realizó directamente la nominación, hubo ocasiones en que las candidaturas vinieron propuestas por los Comités locales o de Sección, o a través de asambleas de liberales de los distritos rurales ${ }^{8}$; otras veces el Comité se limitó a

${ }^{8}$ En 1884, cinco liberales del distrito de Durango se dirigieron al Comité comunicándole la convocatoria de una asamblea para designar al candidato, procedimiento que fue aprobado por éste; en las municipales de 1889 en Bilbao, la Junta nombró subcomisiones en los distritos para que éstos propusieran al Comité los candidatos AVL, leg. 10, doc. 86, 1 de marzo de 1884 y leg. 11 doc. 38. Bilbao, 1 de diciembre de 1889. 
dar su aquiescencia a la candidatura de personalidades relevantes que concurrian en distritos rurales en los cuales tenían la suficiente influencia como para hacer frente a la elección por sí mismos (elecciones a Cortes: Ángel Allendesalazar en Guernica, Manuel Allendesalazar en Marquina, Víctor Chavarri en Valmaseda, etc.). En cuanto a su participación en la campaña, ésta era variable: en el distrito de Bilbao, donde disponia de una amplia infraestructura electoral con agentes y delegados repartidos por todas las secciones, llevaba el peso principal, mientras que en los distritos rurales su actividad estaba más limitada, reducida a la recomendación de los candidatos a aquellos notables sobre los cuales tenia alguna relación. También su contribución económica a las campañas eran variables, en función de la capacidad económica personal de los candidatos; de todos modos, y de forma genérica, podemos indicar que en los distritos rurales su aportación era generalmente pequeña mientras que en el de Bilbao, el Comité, bien directamente o mediante aportaciones individuales de algunos miembros del mismo (pagaban facturas de los agentes de una sección), corría con la mayor parte de los gastos.

En cuanto a los métodos o procedimientos empleados, la documentación conservada en el archivo de Victoria de Lecea, aunque parcial e incompleta, proporciona un conocimiento detallado de los mismos. En la mayor parte de los pueblos, el Comité disponía de una o varias personas de su confianza que, entre otras tareas, informaba de la situación en que se encontraban los electores y el medio por el que podian ser influidos. En la relación que el Comité manejó respecto de Sopelana y Urdúliz para preparar la elección general de 1891, se especifican los siguientes conceptos de los electores: "nombre del elector", "nombre de los caserios", "relación por la que se puede conseguir el voto", "dueños de los caseríos», y «nombres de las personas más influyentes de la localidad». En el apartado de "relacion por la que se puede conseguir el voto", se especifica la forma en que se puede acceder a él en caso de voto dudoso, con comentarios como "hará lo que le diga el médico de Sopelana", "hará lo que le diga el Sr. Zuloaga o su cuñado Pagola de Munguía", «inquilino Marqués Torrecilla", etc. $Y$ en el de personas influyentes se cita el médico, el cura, el farmacéutico, además de un capitán de la marina mercante ya retirado que al parecer gozaba también de cierta influencia en el pueblo. De este modo, el Comité movilizaba y coordinaba la influencia personal de sus adherentes y simpatizantes, tejiendo con los años una verdadera red de influencias una forma de clientelismo común por otro lado al Partido Carlista.

El apoyo que tuvieron del Gobierno también les dio la oportunidad para aprovechar aquellas parcelas de poder dependientes del mismo. En este aspecto es bien conocido cómo el Concierto Económico generó una 
administración autónoma que restó influencia al Gobierno, quien no tenía facultades para suspender alcaldes, ni disponía de un cuerpo de funcionarios, por citar sólo algunos ejemplos. Estas limitaciones impidieron la implantación de un caciquismo en niveles y formas análogas a las del resto del pais. Sin embargo, el Gobierno disponia aún de ciertos resortes y competencias que, convenientemente utilizadas, le proporcionaban cierta influencia en el Pais. Este era el caso de las Aduanas, de la administración de justicia, de las loterías, estancos, quintas, policia y orden público, además de la influencia que la politica económica podia tener sobre determinados sectores económicos; asi, la posición proteccionista del Gobierno afectaba al sector metalúrgico, igualmente el mercado armero era extraordinariamente sensible a la política gubernamental, en fin, era además el principal cliente de importantes empresas ubicadas en la provincia (caso Astilleros Nervión). La documentación nos permite comprobar la intensa actividad desplegada para influir en los nombramientos de jueces, estanqueros, maestros, asignación de loterias, resolución de expedientes judiciales, expedientes a secretarios de ayuntamientos, etc.. Finalmente, también disponia el Gobierno de facultades legales susceptible de alterar las circunscripciones o de regular las condiciones de las convocatorias; asi, hemos tenido ocasión de poner de relieve en un estudio anterior cómo la creación del distrito de Marquina en 1884 se hizo con el único objeto de favorecer a los liberales dinásticos (gerrimanderyng) ${ }^{9}$.

Pero el medio de influencia que mas ha atraído la atención de los historiadores en el ámbito vasco ha sido el de la compra de votos, quizás por la utilización masiva y escandalosa que del mismo hicieron el grupo de los llamados «industriales» en la década de los noventa. En realidad esta documentación, así como diferentes comentarios realizados por políticos varios años después, demuestran su uso en la década de los ochenta, e incluso antes, por parte de la clase politica tradicional, tanto liberal como carlista, aunque no en los niveles y formas que posteriormente alcanzaria. El Marqués de Acillona justificaba en 1903 la compra de electores en la disputa del acta a Cortes de Marquina, en el hecho de que, "... desde que en Vizcaya se conocen las elecciones ha sido costumbre obsequiar a los electores rurales con una frugal comida el dia de la elección ${ }^{10}$ ". Y en la mismo año, el diputado electo católico por Bilbao, José María Urquijo, se defendió de la misma acusación alegando que «la compra es algo que se hace corrientemente y por todos". Confirmando estos comentarios, sabemos que el Comité Liberal obsequiaba a todos

9 Real Cuesta, Javier, El Carlismo Vasco..., págs. 211-212.

${ }^{10}$ La Gaceta del Norte. Bilbao, 16 marzo 1903. 
sus electores con comida y bebida, algo que al parecer también se hacia antes, según decia un agente electoral en 1882: "es uso establecido y generalizado por los candidatos que a todo elector que emita su voto se les da de comer y beber ese día de la elección" ". También hemos encontrado algún ejemplo de compra de votos en esta década, pero ni el número ni su precio fueron importantes ${ }^{12}$. La diferencia por tanto respecto de la década siguiente estuvo en su caracter limitado, pues se trataba de una mínima gratificación que no condicionaba sustancialmente el voto $y$, sobre todo, su cuantia no constituia un obstáculo insalvable para cualquier candidato o grupo político de capacidad económica media.

En la elección general de 1891, sin embargo, el Comité modificó esta fórmula tradicional, utilizada en mayor o menor medida por todas las fuerzas politicas, al invertir grandes sumas de dinero en la compra masiva de votos. No se trataba entonces de "obsequiar" sino "comprar" a los electores, práctica que pronto se haria habitual y que provocaria la destrucción del clientelismo, del caciquismo tradicional. Para apoyar la candidatura de Fernando Victoria de Lecea por el distrito de Bilbao, acometió una organización electoral minuciosa nombrando Jefes de Sección a los cuales les asignaron varios agentes pagados encargados de trabajar la elección. De este modo, el Comité tuvo información detallada de los conceptos por los que eran influenciables los electores; aquellos que no lo eran por lazos de amistad o dependencia, fueron comprados por dinero en cantidades variables, desde los 14 votos de Gatica pagados a 5 pts. por voto, hasta las 50 pesetas que se pagaron en Berango; en la capital, de los 26 votos comprados en la sección 2, el 90 por 100 osciló entre las 10-15 pesetas, al igual que los 76 votos comprados en la sección 1. A esto hemos de añadir el pago de los mismos agentes, regalos a electores, comidas, transportes, etc. con lo que el gasto total realizado en la elección ascendió a 39.256 pesetas, lo que era una cantidad considerable, de las cuales el 39,3 por 100 se destinó al pago de electores y el resto para los agentes, comidas, coches, etc.. Respecto del capitulo de "pago a electores" y según los gastos realizados en las dos primeras secciones (únicas de las que disponemos de datos), se deduce que en el área urbana se destinó mas dinero a la compra de votos que en la rural, donde, por otra parte, la mayor parte del dinero se utilizó para el pago de comi-

\footnotetext{
"Felipe Montanchez al Comité Liberal, 10 Diciembre 1882, AVL., leg. 8, doc. 21. En la documentación del Comité se encuentran varias notificaciones de gastos por este concepto.

${ }_{12}$ En 1882 el alcalde y el secretario de Lauquiniz presentaron al Comite una cuenta de 600 reales por conseguir 35 votos en favor del candidato a las elecciones provinciales Fermin Arnedo. AVL., leg. 8, doc. 28.
} 
das y bebidas ( 3.368 pesetas), tal y como venia haciéndose tradicionalmente ${ }^{13}$.

Tras esta elección, el Comité cederia el protagonismo politico-electoral en favor de una burguesia distinta, recientemente enriquecida gracias a las actividades industriales. Ésta utilizaria la compra de votos en niveles tales, que romperia los mecanismos tradicionales de articulación y expresión política de la sociedad: condicionamiento absoluto del voto, expulsión del sistema de las fuerzas politicas incapaces de competir económicamente con ellos, destrucción en definitiva del clientelismo tradicional.

"Ya no hubo elecciones de candidatos liberales - decia el marqués de Acillona- en que no se derrochara dinero. Pedro P. Gandarias y Manuel Allende presentaron a sus hijos en Guernica: el primero gastó un millón de pesetas y el segundo 400.000, Manuel M. Arrótegui venció al conde de Montefuerte por haberse gastado más dinero (...). Con dinero derrotó Rodas a su contrincante en Marquina y a Eduardo Aznar. Cansados de estos derroches de dinero, los mismos liberales formaron La Piña (...) ${ }^{14}$.

Finalmente, desde el punto de vista político, la presencia del Comité tuvo efectos electorales muy favorables para las fuerzas dinásticas liberales por cuanto pudieron obtener la hegemonia político-electoral en la provincia frente a las fuerzas tradicionalistas. En efecto, por lo que respecta a las elecciones a Cortes, todos los electos en la década fueron dinástico-liberales, excepto un tradicionalista; también en la Diputación obtuvieron cómodas mayorias frente a los grupos tradicionalistas, fueristas y republicanos; y en cuanto a las elecciones locales, en Bilbao, donde los republicanos gozaban de mayor implantación, también obtuvieron amplias mayorias ${ }^{15}$. De este modo, miembros significados del Comité, monopolizaron la presidencia de la Diputación, la alcaldia de Bilbao y la representación a Cortes, situación muy distinta a la de Álava y Guipúzcoa donde las fuerzas tradicionalistas continuaron ostentando la hegemonía.

${ }^{13}$ En la primera sección (calles Artigas, Ibaizabal y Amézola), de las 999 pesetas que costó la elección, el 37,5 por 100 se destinó al pago de los agentes y el resto para la compra de votos; en la Segunda sección (calles Bilbao La Vieja y Cantarrana), de las 1386 pesetas gastadas, 40,4 por 100 lo fueron para los agentes. AVL., leg. 12, docs. 104 y $104 \mathrm{e}$.

${ }^{14}$ La Gaceta del Norte, 16 de marzo de 1903.

15 En 1881 obtuvieron 11 concejales por seis los republicanos, en 188310 frente a ocho, en 188712 (unidos a los fueristas) por cuatro. Datos recogidos de YBara, Javier de, Politica Nacional en Vizcaya. Madrid, Editora Nacional, 1948. 